\title{
The effect of groundwater petroleum hydrocarbons contaminants on chlorine removal in Basra city (south of Iraq): An application of mixed technology of permeable reactive barrier
}

\author{
Saad Abu-Alhail Arab* and Rusul Naseer Mohammed \\ College of Engineering, University of Basrah, 61004, Basra city, Iraq \\ *Corresponding Author: saad.arab@uobasrah.edu.iq
}

$\begin{array}{ll}\text { Submitted: } & 01 / 10 / 2020 \\ \text { Revised: } & 15 / 12 / 2020 \\ \text { Accepted: } & 22 / 12 / 2020\end{array}$

\begin{abstract}
Petroleum hydrocarbon contaminants in groundwater are among the most impactful environmental problems in oil production in southern Iraq, especially Basra city. Petroleum hydrocarbon contaminants affect related projects surrounding the primary pollution site. Benzene, toluene, and dimethylbenzene are the most toxic pollutants affecting the removal of perchloroethene $\left(\mathrm{Cl}_{2} \mathrm{C}=\mathrm{CCl}_{2}\right)$ and trichloroethene $\left(\mathrm{C}_{2} \mathrm{HCl}_{3}\right)$ in groundwater. These pollutants have high solubility in water, leading to their transport over long distances in groundwater and difficult removal. The influence of petroleum hydrocarbons on the chlorine removal of perchloroethene and trichloroethene was studied using a polytetrafluorethylene column packed with zero-valent iron (ZVI). Batch experiments were implemented to investigate the equilibrium supply of mixtures between the aqueous and solid stages in packed column systems. It was designated using the Freundlich isotherm expression, and the result showed that $\mathrm{R}^{2}$ was greater than 0.97 for benzene, toluene, and xylene. The column study noted that the reaction constant was decreased in all columns by approximately $48 \%$ when the pore volume was between 50 and 205, which reflects the dechlorination priority of P-CE over T-CE. These findings indicate that benzene and toluene are more effective for adsorption on the ZVI particle surfaces owing to disparate influences.
\end{abstract}

Keywords: Chlorinated Solvents; Groundwater Pollution; Petroleum Hydrocarbons.

\section{INTRODUCTION}

Hydrocarbon contamination is a significant global problem caused by several factors; petroleum hydrocarbons are specifically problematic owing to their toxicity to all organisms (Aniefiok et al., 2016). Petroleum production has contributed to the energy requirements of nations worldwide and is regarded as a central support of the contemporary global economy, especially in Iraq (Lucy et al., 2011; Hafiz et al., 2016). Basra city is in southern Iraq and has the most oil wealth in the country. This region houses numerous refineries from more than 14 fields and a large net of oil fraction pipelines, which have a high potential for causing groundwater pollution. Several pollutants, such as benzene $\left(\mathrm{C}_{6} \mathrm{H}_{6}\right)$, toluene $\left(\mathrm{C}_{7} \mathrm{H}_{8}\right)$, and dimethylbenzene, are highly soluble in water. Thus, these pollutants travel long distances in groundwater, making them difficult to remove. In addition, pollution of groundwater 
owing to mixed organic compounds is commonly observed, such as the mixed plume of chlorinated solvents such as perchloroethene $\left(\mathrm{Cl}_{2} \mathrm{C}=\mathrm{CCl}_{2}\right)$ (P-CE) and trichloroethene $\left(\mathrm{C}_{2} \mathrm{HCl}_{3}\right)$ (T-CE) (APAT, 2006). Various physical, biological, and chemical processes have been used for treating groundwater pollutants, including adsorption, oxidation-reduction, precipitation, and degradation (Cynthia and David, 1997). These approaches contain mediators to prevent plume formation and avoid the movement of the contaminant source. Permeable reactive barriers have continual building, semi-continual, or expendable elements through the flow way of a liquefied pollutant plume and have been analyzed in previous studies (Eykholt and Sivavec, 1995; Vidic and Pohland, 1996]. This is the best method for treating groundwater pollutants such as chlorinated solvents, benzene, toluene, and dimethylbenzene by reducing chlorinated hydrocarbons using zero-valent iron (ZVI) (William and Lynn, 2000). A previous study demonstrated chlorine removal from chlorinated solvents in mixtures with hydrocarbon components that affect the chlorine removal of chlorinated solvents through ZVI (Gillham and Hannesin, 1994). Furthermore, for mixtures containing other materials such as natural organic matter, other investigators (Chenju L et al., 2007; Xiaohong et al., 2014) reported that naphthalene degradation and benzene, toluene, and dimethylbenzene removal using free biological permeable reactive barriers yield good effects, resulting in high removal rates. The biodegradation of benzene, toluene, and dimethylbenzene has been examined and indicates the utility of this approach as an effective treatment method for tainted groundwater (Fei et al., 2014; Kevin et al., 2008; Amy and Makram, 2004; Robledo et al., 2011). Previous studies have commonly revolved around using one technique to treat a single contaminant; scarcely have any convincing strategies been developed to remove mixed contaminants in groundwater, mainly in view of the variety in synthetic properties of plumes. However, other researchers (Truex et al., 2011) implemented batch experiments to study the effect of hydrocarbon compounds on the chlorine removal of P-CE and T-CE by ZVI. This approach resulted in a decrease in P-CE and T-CE sorption to more than $60 \%$ using on ZVI; however, there was no effect on T-CE degradation and an increase of $50 \%$ concerning P-CE reduction rates. In this study, a column experiment was conducted to observe the influence of benzene or toluene on the dechlorination of mixed P-CE and T-CE by ZVI owing to their potential differences. This paper focuses on the simulation of benzene and toluene for mixed contaminant removal in groundwater, which is generally attributable to the distinction in properties of blended plumes. In addition, the effects of column rates and bed height were investigated and are reported herein.

\section{MATERIALS AND METHODS}

\section{GROUNDWATER SAMPLE COLLECTION}

The samples were analyzed in laboratories of the Basra Environment Directorate-Division of Environmental Analysis; thirteen parameters were evaluated, including chloride $\left(\mathrm{Cl}^{-}\right)$, total dissolved solid (TDS), bicarbonate $\left(\mathrm{HCO}^{-3}\right)$, electrical conductivity $(\mathrm{EC})$, calcium $\left(\mathrm{Ca}^{+2}\right)$, total hardness $(\mathrm{TH})$, nitrate $\left(\mathrm{NO}^{-3}\right)$, magnesium $\left(\mathrm{Mg}^{+2}\right)$, phosphate $\left(\mathrm{PO}_{4}\right)$, sulfate $\left(\mathrm{SO}_{4}^{-2}\right)$, sodium $\left(\mathrm{Na}^{+}\right)$, and potassium $\left(\mathrm{K}^{+}\right)$. The groundwater utilized in all examinations was first exchanged with nitrogen to lessen the breakdown of oxygen to under $1 \mathrm{mg} / \mathrm{L}$. Samples were obtained from four regions to test benzene, toluene, and xylene, with purity $>99 \%$, and ethylbenzene from MERCK with purity $>99 \%$. These pollutant samples were liquefied in distillated water to obtain the desired concentration at impatient temperature. The concentrations of P-CE, T-CE, benzene, toluene, and ethylbenzene were selected for high-performance liquid chromatography (LC-20AD HPLC). The average value of the ground water sample is shown in Table 1. 
Table 1. Average parameter values of groundwater samples.

\begin{tabular}{cc}
\hline Parameter & Average value \\
\hline $\mathrm{pH}$ & 7.45 \\
$\mathrm{TDS}$ & $6,167.7$ \\
$\mathrm{EC}$ & $8,412.0$ \\
$\mathrm{Cl}^{-}$ & $2,196.3$ \\
$\mathrm{CaCO}_{3}$ & $2,258.4$ \\
$\mathrm{HCO}_{3}^{-}$ & $2,151.4$ \\
$\mathrm{NO}_{3}^{-}$ & 26.4 \\
$\mathrm{Ca}^{+2}$ & 612.5 \\
$\mathrm{SO}_{4}^{-2}$ & $1,417.8$ \\
$\mathrm{Mg}^{+2}$ & 202.2 \\
$\mathrm{~K}^{+}$ & 36.3 \\
$\mathrm{Ca}^{+2}$ & $1,417.6$ \\
$\mathrm{PO}^{-3}$ & 0.46 \\
\hline
\end{tabular}

\section{ZVI PREPARATION}

ZVI was prepared from steel and sieved to 10-50 mesh size. The specific surface area of ZVI was $1,990 \mathrm{~m}^{2} / \mathrm{kg}$. The chemical composition of the elements is shown in Table 2.

Table 2. The chemical elements composition in zero-valent iron.

\begin{tabular}{cc}
\hline Chemical elements & Composition\% \\
\hline $\mathrm{Fe}$ & 93.2 \\
$\mathrm{Mn}$ & 1.12 \\
$\mathrm{C}$ & 2.89 \\
$\mathrm{Si}$ & 2.74 \\
$\mathrm{Cr}$ & 0.041 \\
$\mathrm{Ni}$ & 0.032 \\
$\mathrm{Zn}$ & 0.014 \\
\hline
\end{tabular}

\section{EXPERIMENTAL SETUP}

\section{COLUMN EXPERIMENT DESIGN}

A polytetrafluorethylene column with a length of $0.5 \mathrm{~m}$ and a diameter of $0.045 \mathrm{~m}$ was used for the column experiment design. It has six sampling pores, with distances from the inlet of 1.5, 2.5, 6.5, 12.5, 20.5, and $35.5 \mathrm{~cm}$. The column was composed of sand and iron at the same ratio of 0.5:0.5. Groundwater polluted with benzene, toluene, P-CE, and T-CE was forced into the column using a peristaltic pump. In this test, three columns were designed, and water samples were pulled from the sampling pores to investigate benzene, toluene, P-CE, T-CE, and dechlorinated byproducts at room temperature $\left(21-28^{\circ} \mathrm{C}\right)$. The column operating design is summarized in Table 3 . Groundwater containing $7 \mathrm{mg} / \mathrm{L}$ benzene and $20 \mathrm{mg} / \mathrm{L}$ toluene was fed into the packed column for 4 days to fully adsorb benzene and toluene. Then, groundwater of $1 \mathrm{mg} / \mathrm{L}$ benzene was continually fed into the column. When the benzene concentration in the outlet was $1 \mathrm{mg} / \mathrm{L}$, the adsorption saturation of benzene succeeded. 
Table 3. Column operating design.

\begin{tabular}{|c|c|c|c|c|c|c|c|c|}
\hline \multirow{2}{*}{$\begin{array}{l}\text { Compound in column } \\
\text { With Pollutants added }\end{array}$} & \multicolumn{4}{|c|}{$\begin{array}{c}\text { Initial } \\
\text { Concentration }(\mu \mathrm{g} / \mathrm{L}) \\
\end{array}$} & \multirow{2}{*}{$\begin{array}{c}\text { Iron } \\
\text { amount } \\
(\mathrm{kg})\end{array}$} & \multirow{2}{*}{$\begin{array}{c}\text { Flow } \\
\text { rate } \\
(\mathrm{cm} / \mathrm{min})\end{array}$} & \multirow{2}{*}{$\begin{array}{c}\text { Initial } \\
\text { Concentration } \\
(\mu \mathrm{g} / \mathrm{L})\end{array}$} & \multirow{2}{*}{$\begin{array}{c}\text { Porosity } \\
\%\end{array}$} \\
\hline & Benzene & Toluene & P-CE & T-CE & & & & \\
\hline Benzene, P-CE, T-CE & 800 & - & 1350 & 1850 & 1.21 & 0.038 & 800 & 33 \\
\hline Toluene, P-CE, T-CE & - & 940 & 1400 & 1950 & 1.20 & 0.038 & 840 & 34 \\
\hline
\end{tabular}

\section{BATCH SETUP}

Five sequences of batch tests were implemented. First, the absorption and degradation of $5 \mathrm{mg} / \mathrm{L}$ of P-CE and $10 \mathrm{mg} / \mathrm{L}$ of T-CE and the adsorption of benzene and toluene were observed. Second, the relationship between P-CE and T-CE for degradation was investigated. In subsequent tests, the influence of constituents on degradation was investigated using $3 \mathrm{mg} / \mathrm{L}$ of P-CE and $11 \mathrm{mg} / \mathrm{L}$ of T-CE. A two-level concentration of hydrocarbon mixtures was used for each component of $5 \mathrm{mg} / \mathrm{L}$, with a low focus and $100 \mathrm{mg} / \mathrm{L}$ at high fixations. Analyze the separated contaminants by HPLC to determine the equilibrium sorbate concentration $C_{i}$. The sorbate uptake $\left(\mathrm{q}_{\mathrm{e}}\right)$ and removal efficiency were calculated using the following formulae:

$$
\begin{aligned}
& q_{e}=\left(C_{o}-C_{i}\right) \frac{V}{m} \\
& R \%=\frac{\left(C_{o}-C_{i}\right)}{C_{o}}
\end{aligned}
$$

where $\mathrm{m}$ is the mass of the sorbent and $\mathrm{V}$ is the volume of solution (L).

The Freundlich isotherm model was utilized in this study to express the equilibrium distribution of natural compounds between the two phases (solid : liquid) in packed column techniques as follows (Gautham and Prabhakar, 2012).

The region under the sorption isotherm was processed according to the following equation:

$$
q=K_{1} C^{n}
$$

where $\mathrm{q}$ and $\mathrm{C}$ are the adsorbent and aqueous concentrations at equilibrium, respectively. $\mathrm{n}$ is the linear point in the Freundlich model, and $K_{1}$ is the Freundlich isotherm capability in $(\mu \mathrm{mol} / \mathrm{kg}) . \mathrm{n}$ and $\mathrm{K}_{1}$ were calculated using linear regression of the organic log-transformed data, as shown in Table 4.

Table 4. Freundlich model coefficients for adsorption.

\begin{tabular}{ccccc}
\hline Compound & $\mathbf{L o g} \boldsymbol{K}_{\mathbf{1}}$ & $\mathbf{n}$ & Residence time & $\mathbf{R}^{\mathbf{2}}$ \\
\hline benzene & 2.32 & 0.62 & $3-4$ & 0.98 \\
toluene & 2.89 & 0.69 & $3-4$ & 0.97 \\
xylene & 3.25 & 0.62 & $3-4$ & 0.98 \\
P-CE & 2.99 & 0.54 & $1-9$ & 0.96 \\
T-CE & 2.36 & 0.22 & $1-9$ & 0.95 \\
\hline
\end{tabular}




\section{RESULTS AND DISCUSSION}

\section{GAS CHROMATOGRAPHIC ANALYSIS}

High-performance liquid chromatography was performed to compute benzene, toluene, P-CE, T-CE, 1,1-DCE, and vinyl chloride concentrations. In addition, a UV-VIS detector was used to investigate the pollutants situated next to the recorder. The examination result is shown in Figure 1, whereas the base line is limited only in the presence of the mobile phase. The figure shows that benzene control was the first compound that appeared during the peak at 512.

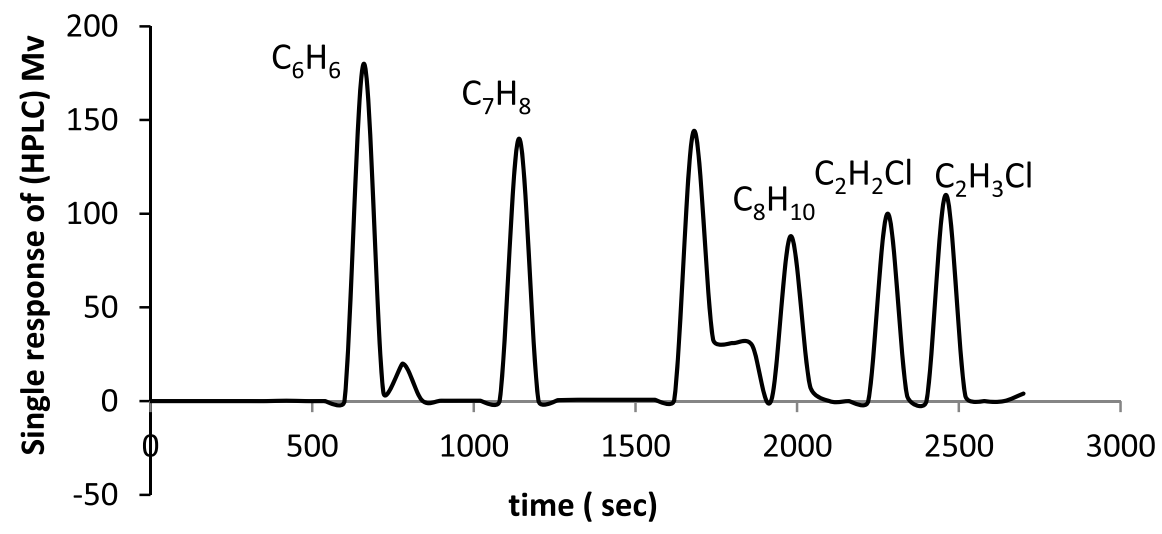

Figure 1. Gas chromatography results for different compounds.

\section{T-CE AND P-CE DECREASE BY BENZENE AND ITS REACTION KINETICS}

The reaction kinetics of T-CE and P-CE dechlorination by ZVI is represented by the quasi-first order (Syful et al., 2020 ) ions that follows in equation (5), and the constant rate $(\mathrm{Ka})$ is determined by the following equation:

$$
C_{t}=\mathrm{C}_{i} / e^{-K_{a} \cdot t}
$$

where $t$ is the reaction time, $C_{i}$ is the initial concentration, and $C_{t}$ is the concentration of T-CE and P-CE reduced at $t$. Figure 2 shows the calculation of the first-order kinetic equation $\left(\mathrm{K}_{\mathrm{a}}\right)$ for T-CE and P-CE. The reaction constant was decreased in all columns by approximately $48 \%$ and clearly when the pore volume (PV) was between 50 and 200, which reflects the dechlorination priority of P-CE rather than T-CE. Similar results were reported in previous studies (Scott and Robert, 1995].

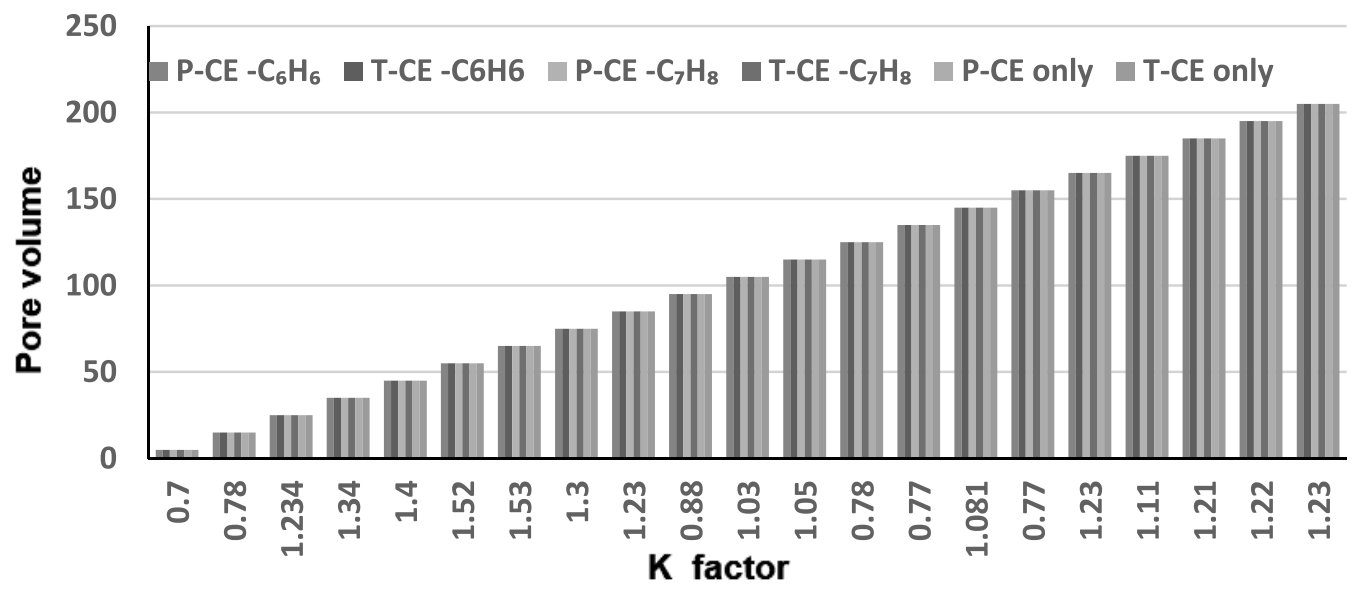

Figure 2. Kinetics reaction constant for P-CE and T-CE. 


\section{MAXIMUM CONCENTRATION ANALYSIS}

Figure 3 shows the maximum concentrations of T-CE, P-CE, and their dechlorination by ZVI packed columns. Maximum concentrations of 4.3, 4.9, and 5.5 for 1, 2-D-CE only, 1, 2-D-CE- $\mathrm{C}_{6} \mathrm{H}_{6}$, and 1, 2-D- $\mathrm{C}_{7} \mathrm{H}_{8}$, respectively, were observed at a PV of 45; then, it was reduced to less than 0.9 at a $\mathrm{PV}$ of 205 . It is also noted that $\mathrm{C}_{2} \mathrm{H}_{3} \mathrm{C}$ without addition did not exceed 1.7 and $\mathrm{C}_{2} \mathrm{H}_{3} \mathrm{C}$ with benzene or toluene did not exceed 0.97 at different PVs. However, the accumulation of dechlorination byproducts (vinyl chloride, benzene, and toluene), especially T-CE, can reduce the dechlorination priority of P-CE. Thus, higher dechlorination of T-CE was observed when column PV ranged from 70 to 205. It was noted that the concentration of $\mathrm{P}-\mathrm{CE}-\mathrm{C}_{7} \mathrm{H}_{8}$ increased to a maximum value of 10.9 at a PV of 65 but decreased to 9 at a PV of 205.

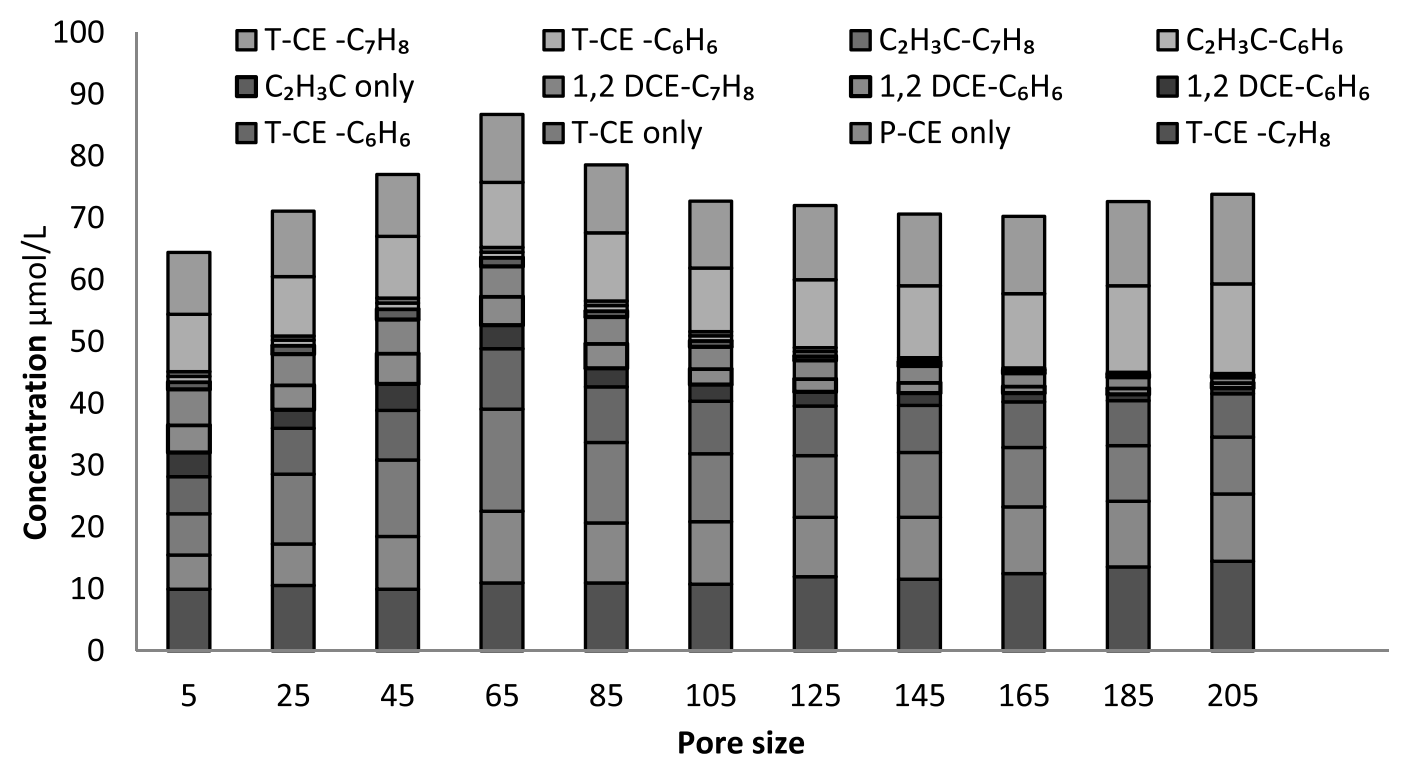

Figure 3. Maximum concentration and dechlorination byproducts of P-CE, T-CE.

\section{KINETICS REACTION FACTOR}

The reaction factor is the ratio of the kinetics reaction of P-CE and T-CE. It was calculated to control the effect of benzene or toluene on the chlorine removal of P-CE and T-CE. Different influences of benzene or toluene on P-CE and T-CE reduction are illustrated in Figure 4 at PVs of 65-90.

Figure 4 shows that the kinetics reaction factor increased to 1.53 and 1.12 at PVs of 65 and 85, respectively, owing to the presence of benzene in P-CE and T-CE, respectively, but the presence of toluene decreased the kinetics reaction factors of $\mathrm{P}-\mathrm{CE}$ and $\mathrm{T}-\mathrm{CE}$ to 0.88 and 0.99 , respectively, at the same PV. No change in the kinetics of the reaction factor was observed when using $\mathrm{P}-\mathrm{CE}$ and $\mathrm{T}-\mathrm{CE}$ without benzene or toluene. The adsorption saturations of benzene and $\mathrm{C} 7 \mathrm{H} 8$ on a column packed with ZVI were attained before P-CE and T-CE were added, and the influences of benzene and toluene might be generally controlled by the adsorption ability of benzene, toluene, P-CE, and T-CE on ZVI. Two types of adsorption sites reaction and non-reaction active sites were noted on the ZVI surface, and the adsorption and dechlorination of P-CE and T-CE occurred on the non-reaction active site. Previous studies have demonstrated that only a few P-CEs and T-CEs were adsorbed on iron oxide minerals, ZVI, and iron carbide of ZVI (David et al., 1998). A previous study (Jan et al., 2004) showed that the adsorption of benzene and toluene on ZVI occurred on the non-reaction site owing to nonlinear isothermal adsorption, and adsorption ability was expressed using the Freundlich constant (Table 4). Figure 4 shows that the maximum PV ranged from 20 to 100, and the kinetics reaction factor ranged from 0.5 to 1.5 . P-CE was replaced with T-CE as the reaction active site of ZVI, owing to its 
higher Freundlich constant and enhancing the dechlorination rate, whereas the initial adsorption saturation on the nonreaction site increased the adsorption probability of P-CE and T-CE by benzene. In addition, for toluene, the initial adsorption saturation of toluene on the non-reaction site increased the adsorption possibility of P-CE and T-CE on the reaction active site of ZVI. However, organic compounds can transfer electrons and increase the speed of chlorine by ZVI (Ruey and Yen, 2005). This result was achieved owing to the higher polarity of benzene (3) compared with toluene (2.4) from the ZVI surface to P-CE and T-CE. A previous study showed the influence of benzene and toluene on the chlorine removal of single P-CE and T-CE. They found that benzene enhanced the P-CE chlorine removal rate by 14 $\%$, although toluene decreased the dechlorination rate by $14.2 \%$. It was concluded that there were different influences on T-CE chlorine removal with or without P-CE compared to the chlorine removal of mixed P-CE and T-CE.

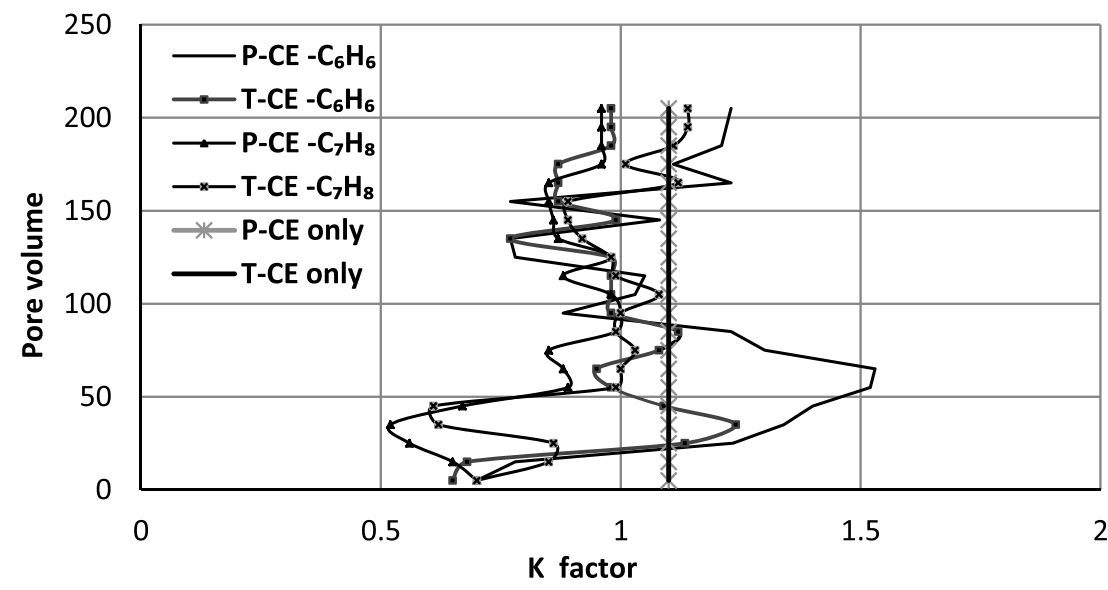

Figure 4. Kinetics reaction factor (K factor) in packed column.

\section{SECONDARY PRODUCTS}

In this study, secondary compounds were products in the columns at a PV of 40 , including ethane $\left(\mathrm{C}_{2} \mathrm{H}_{6}\right)$, ethylene $\left(\mathrm{C}_{2} \mathrm{H}_{4}\right)$, 1,2-dichloroethylene (1,2 DCE), and vinyl chloride $\left(\mathrm{C}_{2} \mathrm{H}_{3} \mathrm{Cl}\right)$ as shown in Figure 5. This indicates that the pathways of chlorine removal transformed P-CE to T-CE, T-CE to 1,2 DCE, and the last one to vinyl chloride. Vinyl chloride was transformed to ethylene via a hydrogenolysis reaction. Thus, dechlorination processes led to a change in all ethylene to ethane through a hydrogenation reaction. The carbon mass balance in the columns at a PV of 80 was also calculated (Figure 6) to be between $67.1 \%$ and $90 \%$ on average. It decreased along the column from 90.3 to 72.3 using benzene and to 67 when using $\mathrm{C}_{7} \mathrm{H}_{8}$. This decrease may be due to the adsorption and volatilization of some secondary compounds, and some secondary products were not quantified in this study.

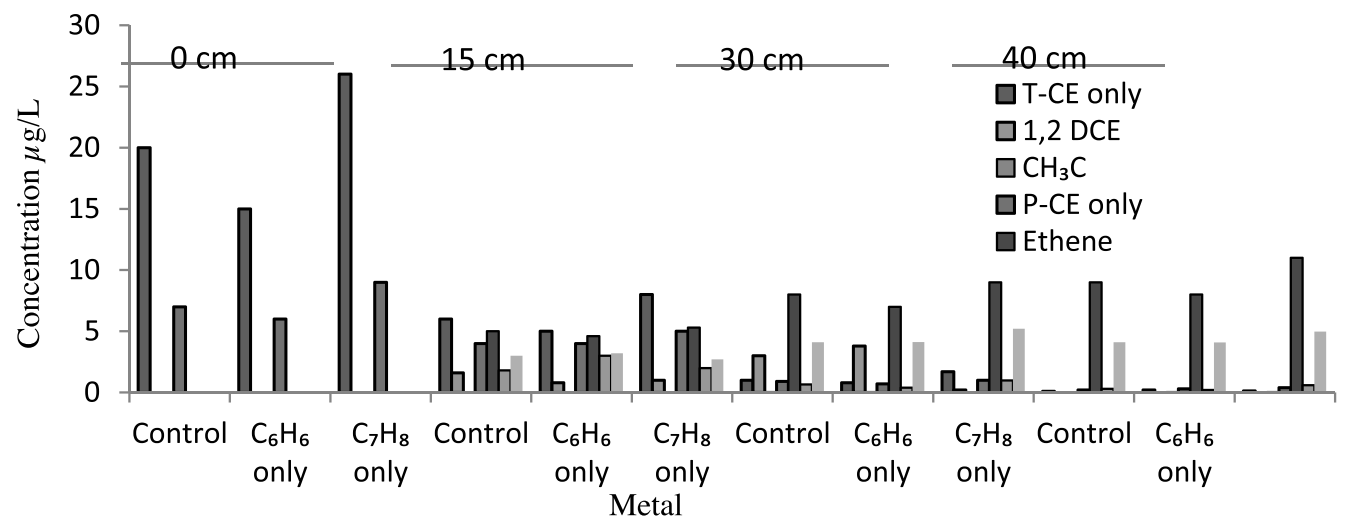

Figure 5. Secondary compounds of $\mathrm{P}-\mathrm{CE}$ and T-CE. 


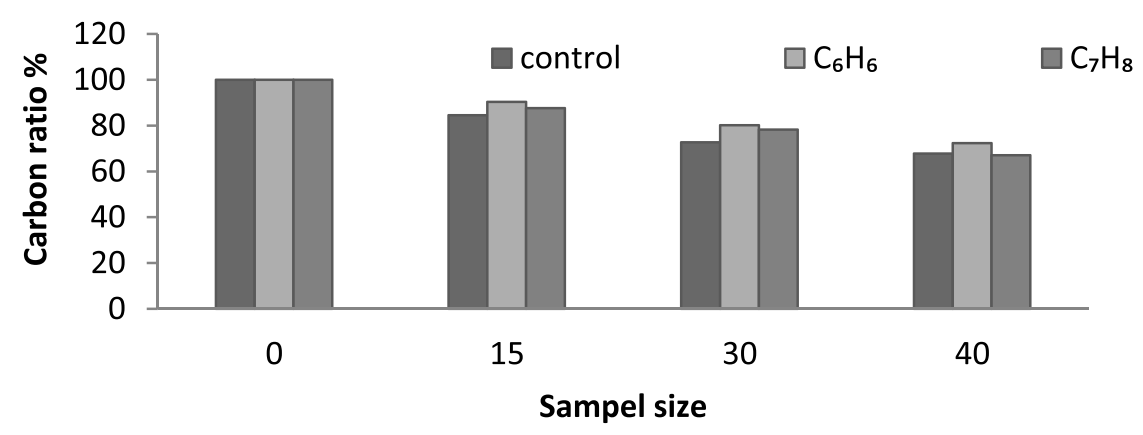

Figure 6. Column compounds carbon ratio at different sizes.

\section{PACKED COLUMN STUDY}

Bed height and flow rate were evaluated to investigate the breakthrough profile.

\section{Effect of bed height}

The effects of bed height on the chlorine removal of P-CE and T-CE in columns filled with ZVI were investigated at flow rates of $0.0277 \mathrm{~cm} / \mathrm{min}$. Different depths of $0.15,0.25$, and $0.35 \mathrm{~m}$ were selected. Figure 7 shows that the saturation points increased when the depth height increased from 0.15 to $0.35 \mathrm{~m}$.

The breakthrough time required was $144 \mathrm{~h}$ at $0.15 \mathrm{~m}$, increasing to $216 \mathrm{~h}$ at $0.35 \mathrm{~m}$. As a result, the number of adsorption sites increased as bed height increased, which increased the adsorption capacity and delayed the saturation state of the breakthrough curve.

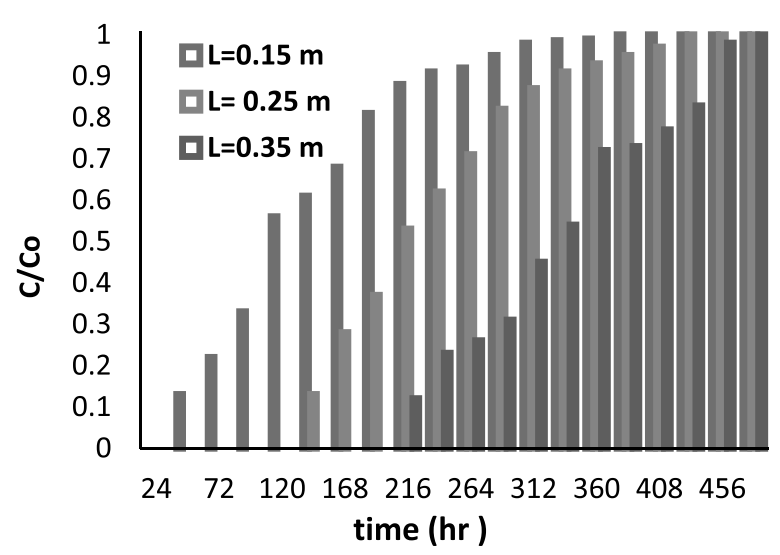

(a) Benzene

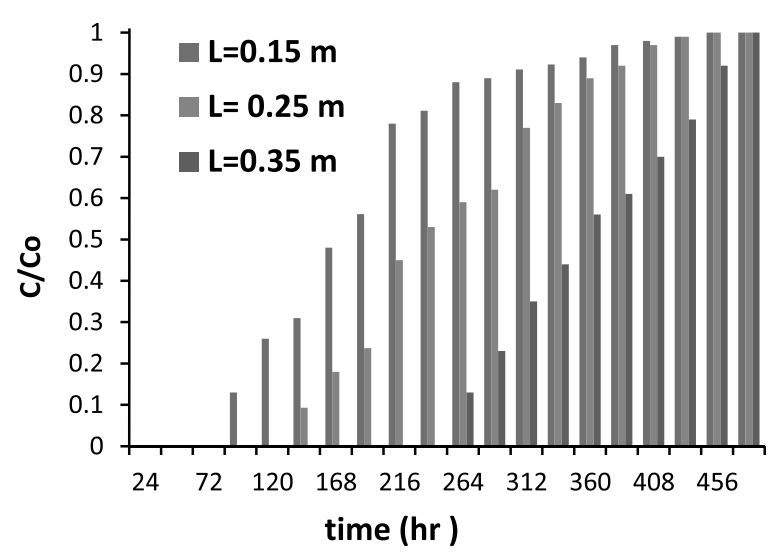

(b) Toluene

Figure 7. Breakthrough curves of P-CE and T-CE chlorine removal at different depths.

\section{Effect of column rates}

The effect of column rates on the adsorption of benzene and toluene was examined at different rates $(0.038$, 0.0277 , and $0.048 \mathrm{~cm} / \mathrm{min}$ ) with a constant depth of $0.25 \mathrm{~m}$. Figure 8 shows that the breakthrough times are influenced greatly by the column rate. It was noted that a long break time is needed with a low rate of $0.038 \mathrm{~cm} / \mathrm{min}$, while the saturation point was achieved at $432 \mathrm{~h}$. As a result, both breakpoint and saturation time decreased by approximately $38-50 \%$ as column rate increased for a given depth height owing to the packed time applied. When the column rate was low $(0.038 \mathrm{~cm} / \mathrm{min})$, benzene and toluene had more time to saturate with packing, leading to an increase 
in pollutant concentrations. At the maximum flow of $0.048 \mathrm{~cm} / \mathrm{min}$, low pollutant removal was observed owing to the insufficient contact between pollutants and the packed material. This reduced the number of active sites, thus decreasing the solution size.

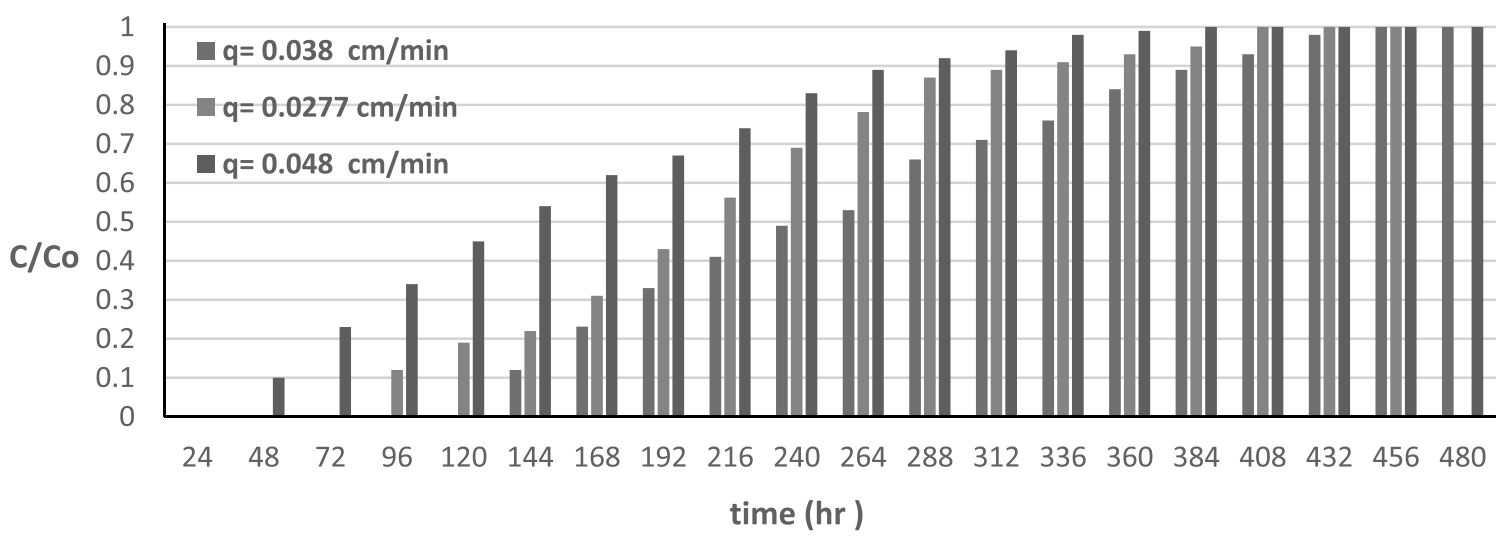

(a) Benzene

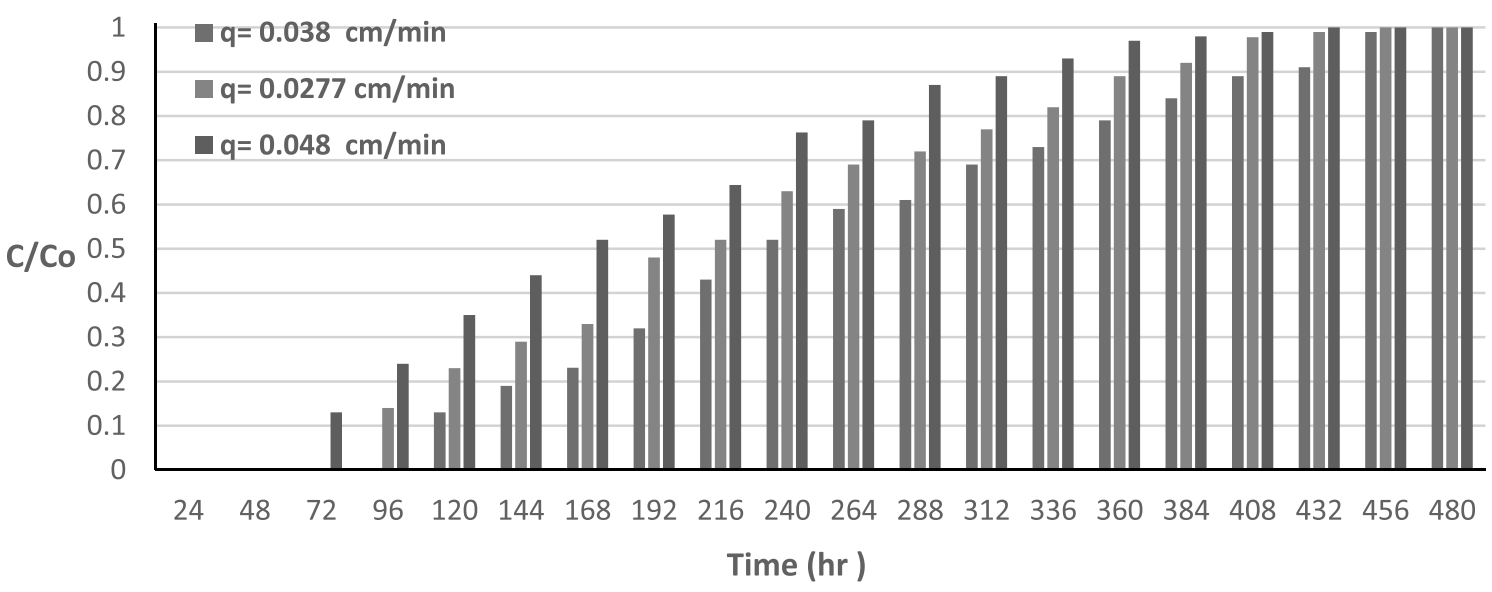

(b) Toluene

Figure 8. Breakthrough curves of chlorine removal of P-CE and T-CE at different column rates.

\section{CONCLUSION}

Basra city has the largest proportion of oil wealth in Iraq. Currently, it houses more than 14 fields. Thus, numerous refineries from these fields and a huge network of oil pipelines pollute groundwater and influence the chlorine removal of P-CE and T-CE. The influence of benzene or toluene on the chlorine removal of mixture P-CE and T-CE was investigated using a column packed with ZVI. This work simulated the biodegradation of benzene or toluene in a ZVI permeable reactive barrier, which could reduce trichlorethylene. Enhancive and inhibitive effects of benzene and toluene, respectively, on P-CE and T-CE decrease were noted at PVs of 20-90 in the columns.

It was observed that increasing the PV from 20 to 200 led to a decrease in the kinetics of P-CE and T-CE by at least $45 \%$. A clear influence of benzene and an inhibitory effect of toluene on P-CE and T-CE decrease were observed at 20-100 PV, but these disparate effects disappeared when PV increased to 220. Furthermore, the chlorine removal advantage of P-CE by ZVI changed due to the different dechlorination locations of P-CE on ZVI, and it decreased with the accumulation of dechlorination by secondary components (ethylene, 1,2 DCE, vinyl chloride, and T-CE), with 
T-CE exhibiting the strongest result. Continuous column experiments results demonstrated that the breakthrough point and removal efficiency increased as bed height increased from 0.15 to $0.35 \mathrm{~m}$ and reduced the feed flow rate.

\section{ACKNOWLEDGMENT}

The authors would like to thank the undergraduate students for their help and the staff of the oil refinery for helping with the special tests used in this research.

\section{REFERENCES}

Amy, P. \& Makram, S. 2004. Effect of benzene, toluene, ethylbenzene, and p-xylene (BTEX) mixture on biodegradation of methyl tert-butyl ether (MTBE) and tert-butyl alcohol (TBA) by pure culture UC1. Biodegradation, 41(15): 213-227.

Aniefiok, E.I., Usenobong, F.U., Margaret, U.I., Idongesit, O.I. \& Udo, J.I. 2016. Petroleum Industry in Nigeria: Environmental Issues, National Environmental Legislation and Implementation of International Environmental Law. American Journal of Environmental, 4(1): 21-37.

APAT. 2006. Manual for Environmental Investigations at Sites Contaminated, Section 5150. Rome: APAT, Manuals and Guidelines 43.

Chenju L., Chiu F.H., Nihar M., Chih J.L. \& Rama M.K. 2007. Hydroxypropyl- $\beta$-yclodextrin-Mediated Iron-Activated Persulfate Oxidation of Trichloroethylene and Tetrachloroethylene. Industrial \& Engineering Chemistry Research, 46(20): 6466-6479.

Cynthia, R.E. \& David, A.D. 1997. Remediation of Metals-Contaminated Soils and Groundwater. Technology Evaluation Report Ground. Water Remediation Technologies Analysis Center P:1-61.

David, R.B., Richelle, M.A., Valipuram, S.M., Timothy, J.C., Gregory, A.L. \& Baolin, D. 1998. Chlorinated ethene reduction by cast iron: sorption and mass transfer. Journal of Environmental Engineering, 124(10): 1012-1019.

Eykholt, G.R. \& Sivavec, T.M. 1995. Contaminant transport issues for reactive-permeable barriers. New York: ASCE.

Fei, L., Roya, G., Cheryl, E., Yunchen, G. \& Laura, A.H. 2014. Metatranscriptome of an Anaerobic Benzene-Degrading, NitrateReducing Enrichment Culture Reveals Involvement of Carboxylation in Benzene Ring Activation, Applied Environmental Microbiology, 80 (14):4095-4107.

Gautham, P.J. \& Prabhakar, T.C. 2012. A modified Langmuir-Freundlich isotherm model for simulating pH-dependent adsorption effects. Journal of Contaminant Hydrology, 130(15): 46-53.

Gillham, R.W.O. \& Hannesin, S.F. 1994. Enhanced Degradation of Halogenated Aliphatics by Zero - Valent Iron. Ground Water 32(6): 958-967.

Hafiz, N.A., Hafiz, M.R., Zahir, A.Z., Muhammad, Y,K., Muhammad, J.A., Muhammad, N. \& Muhammad, S. 2016. Petroleum Hydrocarbons-Contaminated Soils: Remediation Approaches. Soil Science: Agricultural and Environmental Prospective. Springer International publishing chemical P.105-129.

Jan, D., Leen, B., Dirk, S., Spiros, N.A. \& Ludo, D. 2004. Competition for sorption and degradation of chlorinated ethenes in batch zero-valent iron systems. Environmental Science Technology, 38(10): 2879-2884.

Kevin, F., Doug, M., Nick, D. \& Murray E. 2008. Effect of ethanol on microbial community structure and function during natural attenuation of benzene, toluene, and o-xylene in a sulfate-reducing aquifer. Environmental Science Technology, 42(7): 2289-94.

Lucy,. A,. Juliet, C.S. \& Michael, J.C. 2011. The World's Water: The Biennial Report on Freshwater Resources. Fossil Fuels and Water Quality. Washington, DC: Island Press/Center for Resource Economics P.73-96.

Robledo, J.R., Ramírez, D.E., Pérez, A.A., Gómezc, C., González, O., Ramos, J. \& González, R. 2011. Benzene, toluene, and o-xylene degradation by free and immobilized P. putida F1 of postconsumer agave-fiber/polymer foamed composites. International Biodeterioration \& Biodegradation, 65(3): 539-546.

Ruey, A.D. \& Yen, J.L. 2005. Dechlorination of tetrachloroethylene by palletized iron in the presence of humic acid. Water Research, 39(11): 2309-2318. 
Scott, W.O. \& Robert, W.G. 1995. Dechlorination of trichloroethylene. Environmental Science Technology, 30(1): 66-71.

Syful, I., Yanlai, H. \& Weile,Y. 2020. Reactions of chlorinated ethenes with surface-sulfidated iron materials: reactivity enhancement and inhibition effects. Environmental Science Process and impacts, 22(3): 759-770.

Truex, M.J., Macbeth, T.W. \& Vermeul, V.R. 2011. Demonstration of Combined Zero-Valent Iron and Electrical Resistance Heating for In Situ Trichloroethene Remediation. Environmental Science Technology, 45(12): 5346-5351.

Vidic, R.D. \& Pohland, F.G. 1996. Treatment walls, Pittsburgh, PA.Ground Water Remediation Technologies Analysis Center.

William, A.A. \& Lynn, R. 2000. Pathways and kinetics of chlorinated ethylene and chlorinated acetylene reaction with $\mathrm{Fe}(0)$ particles. Environmental Science Technology, 34(9): 1794-1805.

Xiaohong, G., Yuankui, S., Hejie, Q., Jinxiang, L. \& Irene, M. 2014. The limitations of applying zero-valent iron technology in contaminants sequestration and the corresponding countermeasures: The development in zero-valent iron technology in the last two decades. Water Research, 100: 277-295. 